\title{
Productivity Change in Health Care
}

\section{Citation}

Cutler, David and Mark McClellan. 2001. Productivity change in health care. American Economic Review 91, no. 2: 281-286.

\section{Published Version}

http://www.e-aer.org/archive/9102/91020281.pdf

\section{Permanent link}

http://nrs.harvard.edu/urn-3:HUL.InstRepos:2640585

\section{Terms of Use}

This article was downloaded from Harvard University's DASH repository, and is made available under the terms and conditions applicable to Other Posted Material, as set forth at http:// nrs.harvard.edu/urn-3:HUL.InstRepos:dash.current.terms-of-use\#LAA

\section{Share Your Story}

The Harvard community has made this article openly available.

Please share how this access benefits you. Submit a story.

\section{Accessibility}




\title{
Productivity Change in Health Care
}

\author{
By David M. Cutler and Mark McClellan*
}

Research on productivity change in health care has surged in recent years. This interest reflects both policy interest in the value of health care and improving data capabilities and methods for productivity research. Because of the central importance of quality change in health care, this research has directly or indirectly considered not only changes in the costs of producing health services (e.g., the cost of a hospital day), but also changes in the benefits of health services for patient health.

Some studies have compared overall changes in population health to changes in aggregate medical expenditures. For example, recent studies by Kevin Murphy and Robert Topel (1999) and William Nordhaus (1999) suggest that the value to current and future generations of Americans of improvements in life expectancy in recent decades has exceeded $\$ 2$ trillion per year. Accounting for the improvements in ageadjusted functional health that also appear to have occurred in recent decades (e.g., Kenneth Manton et al., 1997) makes the improvement in health even greater. Cutler and Elizabeth Richardson (1999) estimate that, even if only 25 percent of the overall improvement in health is attributable to medical care, then health-care productivity has risen.

Yet translating this into health-care productivity calculations leaves many issues unresolved. It is not immediately clear how to determine the share of health improvements that result from medical care. Further, even if overall productivity improvements have been high, it is possible that many changes in health-care productivity have been less valuable. Identifying areas of high and low past and potential

* Cutler: Department of Economics, Harvard University, Cambridge, MA 02138, and National Bureau of Economic Research; McClellan: Department of Economics, Stanford University, Stanford, CA 94305, Hoover Institution, and National Bureau of Economic Research. We thank the National Institute on Aging for grants provided through the NBER for support for our research. future productivity improvements would be helpful for guiding policymakers.

For all of these reasons, much of the recent research on health-care productivity has focused on explicit analysis of costs and outcomes for certain common, serious health problems, where other factors can be controlled for and relevant inputs and health outcomes can be measured. In this paper, we review the "state of the art" of the evidence on health-care productivity. We first summarize a set of recent productivity studies of common conditions that account for a substantial fraction of overall medical spending. These studies also illustrate the range of methods that have been used in disease-level productivity studies. In general, the studies show rather substantial productivity gains in care. We then present new evidence on productivity of treatment for breast cancer, a disease that, at least in its most common forms in adults, many experts believe has seen little improvement in benefits of care over time. Considering cancer allows us to focus on a condition where there is no presumption that medical care has been worthwhile, and where there are a host of complex issues related to case-finding, the timing of diagnoses, and chronic care. We find that the treatment of cancer has had at best small productivity improvements. Outcomes have improved more on a per-case basis than when considering the population as a whole.

\section{Previous Studies of Health-Care Productivity Change}

Previous studies have measured the productivity of medical care in one of two ways (see Cutler and Ernst Berndt [2001] for detailed discussion). One set of studies has explicitly measured changes in the costs of care and outcomes of population cohorts with specific health problems over time. Cutler et al. (1998, 2001) used longitudinal data on the treatments, hospital costs of care, and health outcomes for the vast majority of elderly Medicare beneficiaries hospitalized with new heart attacks between 1984 
and 1994. They documented a significant improvement in long-term life expectancy of roughly one year per heart-attack patient, due primarily to improvements in acute mortality that persisted for many years.

Valuing years of life is difficult. A common estimate in the literature is that an additional year of life is worth perhaps $\$ 100,000$ (W. Kip Viscusi, 1993). Adjusting for the lower quality of life expected for people with these serious conditions, we use a value of $\$ 75,000$ per year. This estimate is clearly subject to some error; in general, we draw firm conclusions only in situations where a very wide range of values for a year of life give consistent answers. With this assumption, the benefits of medical-treatment changes for heart-attack treatments exceed the costs by $\$ 87,000$ per person with a heart attack, representing a substantial increase in productivity.

Similarly, Cutler and Ellen Meara (2000) used repeat cross-sectional data on childbirth expenditures and mortality from 1950-1990 to quantify the changes in costs and outcomes for childbirth explicitly. Between 1950 and 1990, the average low-birth-weight infant lived an additional 12 quality-adjusted years owing to improvements in medical care in the postnatal period (neonatal intensive-care units, ventilators, etc.). The cost increase was nearly $\$ 40,000$, large but nowhere near as large as the health gains. The net benefit of treatment changes is nearly $\$ 200,000$ per low-birthweight infant.

While direct studies of changes in outcomes and costs of care are perhaps the most compelling approach to evaluating productivity change, studies like these have some limitations. First, it is hard to control for all of the improvements in health outcomes. For each of these conditions, there is evidence that medicaltechnology changes account for the bulk of the health improvement. Paul Heidenreich and McClellan $(2001 \mathrm{a}, \mathrm{b})$ concluded that at most 20-30 percent of the improvement in heartattack mortality during this time period could be attributed to nonmedical factors. Cutler and Meara (2000) argue that, conditional on birth weight, intensive technologies are virtually the only reason for changes in outcomes over time. But such arguments will not always be possible. In addition, it is difficult to measure all of the quality factors that patients value. In the case of heart attacks, we found no evidence of offsetting increases in forms of heart disease such as angina and congestive heart failure that were large enough to alter our conclusions substantially, but we could not look at all possible outcomes.

A second set of studies confronting these problems has chosen a different method of productivity assessment. In particular, they have combined clinical data on the average effectiveness of therapies with administrative data on changes in utilization over time. For example, Ernst Berndt et al. (2000) have estimated the value of recent changes in care for depression by combining the results of clinical studies with data on trends in treatment patterns. Berndt et al. show that, over the 1991-1996 period, there was a large shift of patients away from psychotherapeutic approaches and toward pharmacological management of depression. The cost of this technology change was minimal; pharmaceutical management is actually cheaper than psychotherapy. But the change brought health benefits. More people taking pharmaceuticals received guideline levels of care than was the case when psychotherapy predominated. Thus, average spending per incremental remission of depressive symptoms fell by nearly 20 percent over this time period, effectively an increase in productivity.

Similarly, Irving Shapiro et al. (2001) used a detailed review of the clinical literature on both costs and benefits of surgical treatment for cataracts to evaluate changes in productivity of care for cataracts. Over the past several decades, a range of improvements in surgical techniques and replacement lens devices have dramatically reduced the cost, time, and morbidity associated with cataract extraction procedures. Hospital stays for the surgery have declined from over a week in the early 1950's to only a few hours today, and complications such as infections are much less common. At the same time, improved lenses and techniques have also led to higherquality vision after cataract excision. Shapiro et al. estimate an index of the change in cost of the procedure by multiplying the average use of each major type of medical resource (hospital day, operating room, surgeon) in producing the operation at a given time by the medical price index for that type of input (see Shapiro et al., 
2001 p. 20). By using current prices for each input, they account for the fact that these inputs have generally become more intensive over time. They conclude that the real cost of a cataract excision declined over time by about 1.6 percentage points per year. Although they do not provide an estimate of the change in quality of care, the evidence from the clinical literature of increasing quality strongly suggests that productivity rose.

These indirect studies have their limitations as well. Most importantly, the effects of treatments are likely to be heterogeneous; for example, certain drugs may be effective for treating some depressed patients, while other drugs or psychotherapy may be more effective for others. Because these studies do not directly measure outcome changes, they do not account for potentially important productivity effects in terms of how treatments are allocated. Such allocation quality could either improve over time (better information on who should get what care) or decline (forced standardization resulting from managed care). In addition, as the costs and morbidity of treatment decline, patients with milder forms of disease or earlier stages of disease are likely to receive treatment, which may reduce, or increase, treatment efficacy.

Despite different approaches and different limitations, the direct and indirect studies of productivity changes in the treatment of common diseases universally show that productivity is rising, and by large amounts (see Table 1). Still, while the conditions reviewed here account for around one-sixth of medical spending, it is possible that they are not representative. In particular, chronic diseases such as diabetes and congestive heart failure, for which no "curative" procedures exist, have been understudied. Further, the clinical evidence suggests that health outcomes have not improved much for some important conditions, despite innovations in treatment. The most obvious such disease is cancer. Despite a variety of potentially costly innovations in screening and treatment, population mortality rates from breast cancer, an important outcome measure for the condition, did not decline through the 1980's and have fallen only modestly in very recent years.
Table 1-Estimates of Productivity Change in Treatment of Common Health Problems

\begin{tabular}{|c|c|c|c|c|c|}
\hline \multirow[b]{2}{*}{ Condition } & \multirow[b]{2}{*}{ Years } & \multirow{2}{*}{$\begin{array}{c}\text { Cost } \\
\text { change } \\
(\$)\end{array}$} & \multicolumn{2}{|c|}{ Outcome } & \multirow[b]{2}{*}{$\begin{array}{l}\text { Net benefit } \\
(\$ 1,000 \text { 's })\end{array}$} \\
\hline & & & Change & $\begin{array}{c}\text { Value } \\
(\$ 1,000 \text { 's })\end{array}$ & \\
\hline Heart attack & 1984-1994 & 7,000 & 1 year ${ }^{2}$ & 94 & 87 \\
\hline \multicolumn{6}{|l|}{$\begin{array}{l}\text { Low-birth- } \\
\text { weight }\end{array}$} \\
\hline Depression & $1991-1996$ & - & b & - & - \\
\hline Cataracts & $1969-1998$ & -364 & c & - & $>0$ \\
\hline
\end{tabular}

Notes: Value assumes that willingness to pay for a year in perfect health is $\$ 100,000$ or about $\$ 75,000$ given quality-of-life disutility from these conditions. Details of particular conditions can be found in Cutler et al. (2001) [heart attacks], Cutler and Meara (2000) [low-birth-weight infants], Berndt et al. (2000) [depression], and Shapiro et al. (2001) [cataracts]. Cost changes were calculated by the authors from reported results.

ancrease in life expectancy.

b Cost per expected remission falls by 20 percent.

' No direct evidence reported; indirect evidence suggests substantial improvements in quality of procedure.

\section{New Evidence on Productivity Change in Breast-Cancer Care}

To expand the range of what is known, we consider the productivity of treatment changes for breast cancer. We analyze cancer registry data from the Surveillance, Epidemiology, and End Results (SEER) program linked to comprehensive Medicare claims records for the vast majority of elderly registry patients diagnosed with new cases of breast cancer between 1984 and 1991. The SEER data provide accurate information on the nature and extent of cancer (e.g., stage). The Medicare claims allowed us to estimate longitudinal costs of treatment, analogous to our previous work on heart attacks. More details are available in our technical paper (Cutler and McClellan, 2001).

As an approximation to the impact of cancer treatment on lifetime medical costs, we calculated the discounted difference in total Medicare expenditures in the eight years after diagnosis (including all types of inpatient, ambulatory, and physician services) for patients with breast cancer versus age-matched beneficiaries without breast cancer. Costs for years beyond our follow-up period (through 1998) were imputed based on the relative spending differences observed for earlier cohorts. The data were linked to complete death index records, including information on whether breast cancer was the underlying cause. We constructed estimates of changes in life expectancy by assuming that the 


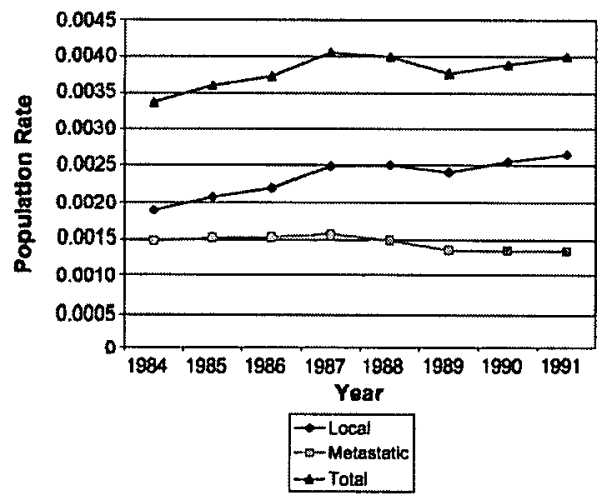

Figure 1. Incidence of Diagnosed Breast Cancer IN THE ELDERLY

Source: Authors' analysis of SEER-Medicare linked data.

same relative differences in survival observed for patients with and without breast cancer during our followup period (through 1998) would continue. Thus, our estimates are based on actual patient follow-up for at least seven years after diagnosis.

With more emphasis on breast-cancer screening through greater use of mammography and other procedures, there was a shift toward earlier diagnosis of breast cancer over time (Fig. 1). This trend included a shift in the timing of diagnosis, from later advanced (metastatic) cases to earlier detection of milder cases. ${ }^{1}$ In addition, there was an increase in the overall rate of cancer detection: the increase in the incidence of local-stage cancer detection more than exceeds the decline over time in metastatic cancer detection. This may reflect two phenomena: either the true incidence of cancer has increased (e.g., because of increases in risk factors such as fewer or later pregnancies and higher income), or more cancers are being detected that previously were not detected and treated (e.g., because the patient died of other causes before the cancer had progressed to a symptomatic stage). Differentiating between these two hypotheses is important. If the change in

\footnotetext{
${ }^{1}$ Other things equal, increased detection will create a temporary increase in the incidence of new cases of an illness, as more cases are identified that would have been detected later, possibly at a more severe stage. In the long run, the overall case incidence will return to its equilibrium level, with a higher share of early-stage cases and a lower share of late-stage cases.
}

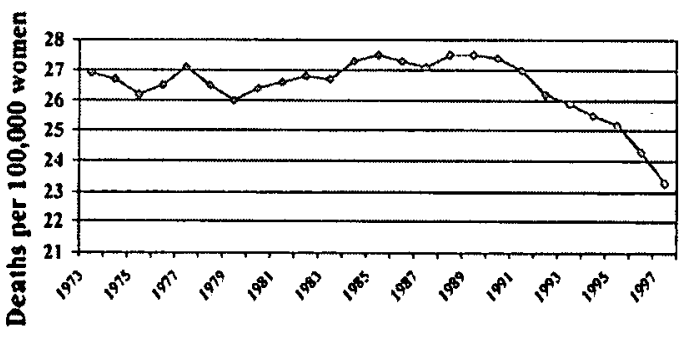

Figure 2. Breast-Cancer Mortality Trends

Source: National Center for Health Statistics.

overall detection is exogenous to medical care, we would not want to count the increased population mortality rate implied by the change as a negative productivity change. But if the change in detection is a result of screening changes, we want to include the costs and benefits of this increased detection change in our productivity calculations. In particular, if more intensive case-finding did not lead to improvements in cancer outcomes, then the per capita costs of cancer care in the population would rise, but population outcomes from cancer would not improve.

Figure 2, which shows trends in demographically adjusted population mortality rates, suggests that increased case-finding may have had some impact on population outcomes. After increasing slightly over the previous two decades, population mortality rates began to decline gradually in 1991. However, because population mortality reflects cancer incidence and outcomes in many preceding cohorts, it is a dampened and delayed measure of the longterm outcome consequences of improvements in cancer care from year to year.

We developed methods for analyzing cohorts of new cancer patients that account explicitly for the changes in treatment rates in the population from year to year. Our case method for analyzing productivity change is analogous to the approach taken in the previous literature of comparing changes in costs and important outcomes for the average patient treated over time. This method assumes that the observed changes in incidence are real (i.e., the underlying cancer rate in the population has risen). Thus, to measure productivity change, we simply compare costs and benefits for diagnosed patients in different years. In contrast, our population method compares changes in the costs and outcomes of breast cancer for the average woman in the 
Table 2-Costs and Beneftrs of Changes in TREATMENT FOR BREAST CANCER

\begin{tabular}{cccccc}
\hline \hline & \multicolumn{2}{c}{ Case method } & & \multicolumn{2}{c}{ Population method } \\
\cline { 2 - 3 } Year & $\begin{array}{c}\text { Average } \\
\text { cost }\end{array}$ & $\begin{array}{c}\text { Life } \\
\text { expectancy }\end{array}$ & $\begin{array}{c}\text { Average } \\
\text { cost }\end{array}$ & $\begin{array}{c}\text { Life } \\
\text { expectancy }\end{array}$ \\
\hline 1985 & $\$ 14,809$ & $8 \mathrm{yr} 5 \mathrm{mo}$ & & $\$ 16,553$ & $\mathrm{NA}^{\mathrm{a}}$ \\
1991 & $\$ 20,160$ & $9 \mathrm{yr} 1 \mathrm{mo}$ & $\$ 25,425$ & $\mathrm{NA}^{\mathrm{a}}$ \\
\hline Change: & $\$ 5,351$ & $\begin{array}{c}8 \mathrm{mo} \\
(\$ 34,886)\end{array}$ & $\$ 8,872$ & $\begin{array}{c}2 \mathrm{mo}^{\mathrm{a}} \\
(\$ 10,997)\end{array}$ \\
\hline
\end{tabular}

Note: Costs are relative to the Medicare population as a whole. The discounted value of life expectancy assumes that a year is worth $\$ 75,000$.

"NA = not available. Population life expectancy change attributable to changes in breast cancer outcome is calculated from the increase in population life expectancy corrected for the increase in breast cancer incidence.

population. This method assumes that the observed changes in incidence are a result of increased detection of "subclinical" cases. Thus, increased detection and more intensive treatment are beneficial only to the extent that they actually improve outcomes for the population as a whole. If early detection is on net beneficial, the gains could be even greater than with the case method. But if early detection reflects increased diagnosis and treatment of cases that would not have developed into lifethreatening cases, the change might reduce productivity. ${ }^{2}$

Table 2 summarizes the results. Average spending per case increased substantially, by over $\$ 5,000$ (in 1991 dollars). This increase in expenditures was accompanied by an increase in life expectancy of eight months. Thus, with reasonable valuations of life (e.g., $\$ 75,000$ for a year in good health), the increases in costs have been well worth it, though the gains have been less impressive than for the other conditions reviewed in Table 1. In contrast, the population method suggests that the higher costs of treatment have been roughly commensurate to the value of the life-expectancy gains. A small gain in overall survival has occurred, but the net benefit de-

\footnotetext{
${ }^{2}$ Neither method accounts for the out-of-equilibrium phenomenon discussed in footnote 1; thus, these methods are best applied before and after a change in disease screening occurs.
}

pends importantly on the value of a year of life. No strong conclusion about populationlevel health changes can be drawn from these results, though there is no evidence that productivity declined substantially.

\section{Conclusion}

Though they are not without limitations, recent disease-based studies are providing a new type of evidence on rising productivity in health care. In the case of cataracts and depression, productivity growth appears to have occurred as a result of a decline in per-case treatment costs. In these diseases, total treatment expenditures may well have risen, because of an associated rise in treatment rates as treatment improves. In the case of other serious illnesses, treatment intensity (both in terms of screening procedures and therapies) has risen, leading to increasing per-case expenditures, but also to improvements in outcomes that make the rising intensity worthwhile. Our new results on breast cancer suggest that, even for an illness that has been widely regarded as showing little improvement despite rising costs, productivity has not declined.

Further research should help expand and clarify the emerging picture of health-care productivity growth. First, it is possible that productivity trends in more recent years have been different, as a result of newer innovations and changes in health-care markets. Second, chronic illnesses, such as diabetes or heart failure, and illnesses associated with significant disabilities that often involve longterm supportive care, such as hip fracture or stroke, are increasingly important components of health care. Studies of chronic illnesses will require extensions of the cohort methods used in previous research and more attention to changes in quality of life and their valuation. Third, as a broader range of disease studies becomes available, it should become easier to develop an integrated, patient-level perspective in evaluating health-care productivity. Finally, the emerging methods for evaluating productivity change can be applied in clinical evaluations of new medical treatments, as well as in evaluating the consequences of economic and policy influences on the healthcare system. 


\section{REFERENCES}

Berndt, Ernst R.; Bir, Anupa; Busch, Susan H.; Frank, Richard G. and Normand, Sharon-Lise T. "The Medical Treatment of Depression, 1991-1996: Productive Inefficiency, Expected Outcome Variations, and Price Indexes." National Bureau of Economic Research (Cambridge, MA) Working Paper No. 7816, July 2000.

Cutler, David M. and Berndt, Ernst, eds. Medical care output and productivity. Chicago: University of Chicago Press, 2001 (forthcoming).

Cutler, David M. and McClellan, Mark. "The Productivity of Cancer Care." Mimeo, Stanford University, January 2001.

Cutler, David M.; McClellan, Mark; Newhouse, Joseph P. and Remler, Dahlia. "Are Medical Prices Falling?" Quarterly Journal of Economics, November 1998, 113(4), pp. 991-1024.

. "Pricing Heart Attack Treatments," in

David M. Cutler and Ernst Berndt, eds., Medical care output and productivity. Chicago: University of Chicago Press, 2001 (forthcoming).

Cutler, David M. and Meara, Ellen. "The Technology of Birth: Is It Worth It?" in A. Garber, ed., Frontiers in health policy research, Vol. 3. Cambridge, MA: MIT Press, 2000, pp. 33-67.

Cutler, David M. and Richardson, Elizabeth. "Your Money and Your Life: The Value of Health and What Affects It," in A. Garber, ed., Frontiers in health policy research,
Vol. 2. Cambridge, MA: MIT Press, 1999, pp. 99-132.

Heidenreich, Paul and McClellan, Mark. "Productivity Change in Heart Attack Care, 1975-1995: A Literature Review and Synthesis," in David M. Cutler and Ernst Berndt, eds., Medical care output and productivity. Chicago: University of Chicago Press, 2001a (forthcoming).

. "Trends in Treatment and Outcome for Acute Myocardial Infarction: 1975-1995." American Journal of Medicine, 15 February 2001b, 110(3), pp. 165-74.

Manton, Kenneth; Corder, Larry S. and Stallard, Eric. "Chronic Disability Trends in Elderly United States Population: 1982-1994." Proceedings of the National Academy of Sciences (USA), March 1997, 94, pp. 2593-98.

Murphy, Kevin M. and Topel, Robert H. "The Economic Value of Medical Research." Mimeo, University of Chicago, 1999.

Nordhaus, William D. "Incorporating the Health of Nations in the Wealth of Nations: The Contribution of Improved Longevity to National Income." Mimeo, Yale University, 1999.

Shapiro, Irving; Shapiro, Matthew and Wilcox, David. "Measuring the Value of Cataract Surgery," in David Cutler and Ernst Berndt, eds., Medical care output and productivity. Chicago: University of Chicago Press, 2001 (forthcoming).

Viscusi, W. Kip. "The Value of Risks to Life and Health." Journal of Economic Literature, December 1993, 31(4), pp. 1912-46. 
Copyright of American Economic Review is the property of American Economic Association. The copyright in an individual article may be maintained by the author in certain cases. Content may not be copied or emailed to multiple sites or posted to a listserv without the copyright holder's express written permission. However, users may print, download, or email articles for individual use. 